\title{
Characteristics of Referral Neonates in Sanglah Hospital: Reviewed from the S.T.A.B.L.E Program
}

\author{
(1) CrossMark \\ Dian Sulistya Ekaputria ${ }^{\text {, Made Sukmawatib }}{ }^{\text {, Putu Junara Putrac, I Made Kardana }}{ }^{\mathrm{d}}$, I Wayan Dharma \\ Artana $^{\mathrm{e}}$
}

Manuscript submitted: 18 June 2020, Manuscript revised: 27 July 2020, Accepted for publication: 09 August 2020

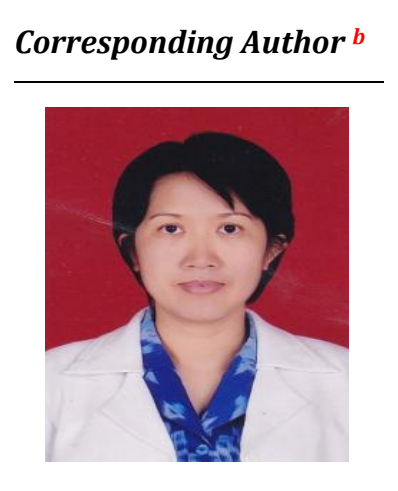

Keywords

characteristics;

mortality;

neonates;

referral;

S.T.A.B.L.E program;

\begin{abstract}
The purpose of this study was to investigate the number of referral neonates that came with an unstable condition (according to a S.T.A.B.L.E program) and characteristic of unstable conditions of the referred neonates. An observational prospective study was conducted for two years from 1st January 2018 to 31st December 2019 in the Emergency Department of Sanglah Hospital, Bali, Indonesia. Referred neonates were assessed in terms of gender, gestational age, referral characteristic, and condition on arrival at the hospital according to S.T.A.B.L.E criteria. According to S.T.A.B.L.E criteria, 283 neonates (54.8\%) came on unstable condition. Prematurity (42.6\%) was the main reason for referral, $37.9 \%$ of them were very low birth weight. Most of them were referred from Denpasar (33.9\%), the equipment of transportation was incubator transport (41.8\%). T-piece resuscitator was used in $30.4 \%$ of referred neonates. Characteristics of unstable conditions were mostly hypoglycemia (33\%) and $36 \%$ of unstable neonates had more than one condition of instability. This study revealed 283 neonates were unstable and the main reason of transfer neonates is prematurity. Most of them come with unstable conditions that could lead to higher mortality. This study could be a reference for improvement in the neonatal transportation system in Bali.
\end{abstract}

International Journal of Health Sciences (C) 2020. This is an open access article under the CC BY-NC-ND license (https://creativecommons.org/licenses/by-nc-nd/4.0/).

\section{Contents}

Abstract 31

1 Introduction. 32

2 Materials and Methods......

a Department of Child Health, Medical School of Udayana University/Sanglah Hospital, Denpasar, Bali, Indonesia

${ }^{\text {b }}$ Department of Child Health, Medical School of Udayana University/Sanglah Hospital, Denpasar, Bali, Indonesia

c Department of Child Health, Medical School of Udayana University/Sanglah Hospital, Denpasar, Bali, Indonesia

d Department of Child Health, Medical School of Udayana University/Sanglah Hospital, Denpasar, Bali, Indonesia

e Department of Child Health, Medical School of Udayana University/Sanglah Hospital, Denpasar, Bali, Indonesia 


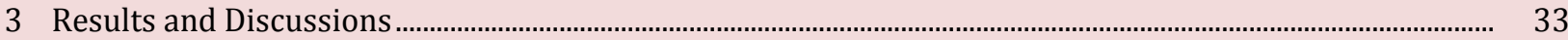

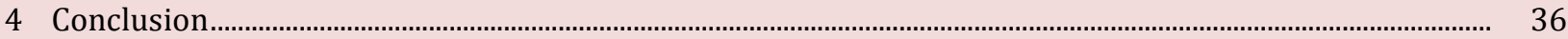

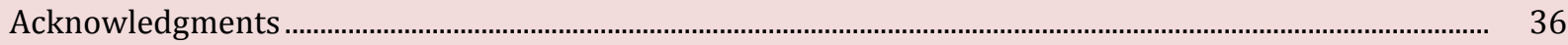

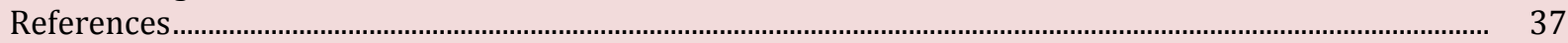

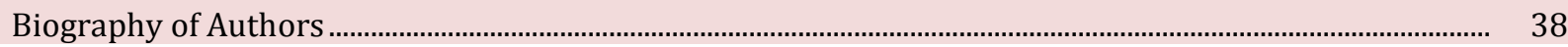

\section{Introduction}

The infant mortality rate is an indicator of health as well as the accessibility of health services by the people in a developing country such as Indonesia. According to WHO (2003), 8,1 million babies died and almost half of it $(3,9$ million or $48 \%)$ occurred in the neonatal period. Almost two-third (2,8 million) of neonatal mortality occurred in the first week of life (World Health Organization, 2003).

Regionalized systems of perinatal care are recommended to ensure that each neonate is delivered and cared for in a facility most appropriate for the neonate's health care needs, when possible, and to facilitate the achievement of optimal health outcomes (Committee on fetus and newborn, 2018). The principle of neonatal transport includes; adequate preparation and stabilization of the baby to be referred, communication with the receiving facility, and provision of standard care similar to that obtained in a neonatal intensive care unit during transfer.

The S.T.A.B.L.E training (sugar and safe care, temperature, airway, blood pressure, laboratory work, and emotional support) program is carried out on health care experts to find and stabilize sick babies after resuscitation or before the baby is referred (Parekh et al., 2018). In the S.T.A.B.L.E program, a sick baby must avoid unstable conditions such as hypoglycemia, temperature instability (especially hypothermia), breathing disorders (hypoxia), and hypoperfusion (shock), and also equipped with laboratory tests and psychological benefits in the form of counseling and educate parents (Parekh et al., 2018; Karlsen, 2018).

In Indonesia, the network of neonatal transport systems hasn't been organized well as in developed countries. Most infants were referred to as unstable conditions. A study in Wahidin Sudirohusodo Hospital in Makassar (2011) found most of the referred neonates were on unstable conditions (64.7\%), which 38.1\% of then were hypothermia and the reason of referral mostly due to infection (38.1\%) (Alasiry, 2016; Batki et al., 2000).

Sanglah Hospital is a tertiary hospital that receives referral patients from all around Bali as well as Nusa Tenggara. Sanglah Hospital has level III of perinatology care. It means that our NICU has prompt and readily available access to a full range of paediatric medical subspecialists, paediatric surgical specialists, paediatric anaesthesiologists, and paediatric ophthalmologists on-site or at a closely related institution by prearranged consultative agreement (Committee on fetus and newborn, 2018).

There was no study before to evaluate the condition of neonates who were referred to Sanglah Hospital. This study aims to investigate the number of referral neonates who come to Sanglah Hospital and characteristics of unstable conditions of these neonates according to the S.T.A.B.L.E program.

\section{Materials and Methods}

This is a descriptive observational study. The data were prospectively collected from all neonates who were referred to the emergency department of Sanglah Hospital from January 2018 to December 2019. The Sample was collected using purposive technique sampling. Data was collected in age, sex, gestation, birth weight, body temperature, blood sugar, oxygen saturation, and laboratory file. Inclusions criteria were neonates who were referred to the emergency department of Sanglah Hospital, Denpasar from January 2018 to December 2019. Exclusions criteria were neonates who died on arrival so did not have the probability to do physical and glucose examination. Subjects were divided into neonates with stable and unstable according to the S.T.A.B.L.E program. The sample size was count using single sample proportion formula and got the sample size is 152 samples. 
The condition of the neonate when referred is an objective condition for identifying neonatal conditions in the emergency department (Biederman et al., 1999; Peterson et al., 2004). Divided into stable and unstable (according to the S.T.A.B.L.E program). The condition is unstable when neonates suffered from: hypoglycaemia, temperature instability, hypoxia, hypoperfusion, or incomplete laboratory workup. Neonates are categorized as hypoglycaemia when peripheral blood sugar levels are $<45 \mathrm{mg} / \mathrm{dl}$ (Null et al., 2016). The body temperature $<36.50 \mathrm{C}$ means the neonate has hypothermia (Null et al., 2016). Neonates experience hypoxia if oxygen saturation is $<88 \%$ while hypoperfusion when capillary refill time is $>3$ seconds (Alasiry, 2016). Incomplete laboratory workup was there is no standard laboratory data on referral (Complete Blood Count and glucose test).

\section{Results and Discussions}

The total neonates admitted to the emergency department of Sanglah hospital during the study period were 516 neonates, of which more than half (54.8\%) were unstable according to S.T.A.B.L.E program. The main reason for referred was preterm birth (42.6\%), 44.3\% of referred neonates were VLBW (weight $>1000$ gram $<1500$ gram). Most neonates were referred from Denpasar (33.9\%). There still 8.5\% of neonates were accompanied without health personnel. Respiratory support used was mostly using a nasal cannula (45.4\%). Characteristics of referred neonates and equipment used during transport were shown in Table 1 and Table 2. Table 3 showed that according to the S.T.A.B.L.E program, most of the neonates were in hypoglycaemia state $(40 \%)$.

Table 1

Characteristic of referred neonates

\begin{tabular}{llll}
\hline Profile of neonates & $\begin{array}{l}\text { Stable } \\
(\mathrm{n}=233)\end{array}$ & $\begin{array}{l}\text { Unstable } \\
(\mathrm{n}=283)\end{array}$ & $\begin{array}{l}\text { Total } \\
(\mathrm{n}=516)(\%)\end{array}$ \\
\hline Birth weight & 92 & 50 & $142(27.5)$ \\
$\quad$ Normal weight & 49 & 76 & $125(24.2)$ \\
Low birth weight (LBW) & 74 & 122 & $196(37.9)$ \\
$\quad$ Very low birth weight (VLBW) & 18 & 35 & $53(10.4)$ \\
$\quad$ Extremely low birth weight (ELBW) & & & \\
Gestational age & 18 & 27 & $45(8.7)$ \\
$\quad$ 28 weeks & 71 & 84 & $155(30)$ \\
28- 32 weeks & 49 & 71 & $120(23.3)$ \\
$>32-36$ weeks & 95 & 101 & $196(38)$ \\
$>36$ weeks & & & \\
Reason for referral & 76 & 144 & $220(42.6)$ \\
Preterm/low birth weight & 50 & 45 & $95(18.4)$ \\
Respiratory distress & 31 & 32 & $63(12.2)$ \\
Birth asphyxia & 44 & 26 & $80(15.5)$ \\
Sepsis & 22 & 36 & $58(11.5)$ \\
Other & & & \\
Referring district & 51 & 124 & $175(33.9)$ \\
Denpasar & 49 & 27 & $76(14.7)$ \\
Badung & 23 & 33 & $56(10.8)$ \\
Gianyar & 18 & 22 & $40(7.8)$ \\
Jembrana & 20 & 10 & $30(5.8)$ \\
Singaraja & 72 & 67 & $139(27)$ \\
Other & & & \\
\hline & & & \\
\hline
\end{tabular}

Ekaputri, D. S., Sukmawati, M., Putra, P. J., Kardana, I. M., \& Artana, I. W. D. (2020). Characteristics of referral neonates in Sanglah Hospital: reviewed from the S.T.A.B.L.E program. International Journal of Health Sciences, 4(2), 31-39. https://doi.org/10.29332/ijhs.v4n2.447 
Table 2

Equipment used during transportation

\begin{tabular}{llll}
\hline Equipment used during transport & $\begin{array}{l}\text { Stable } \\
(\mathrm{n}=233)\end{array}$ & $\begin{array}{l}\text { Unstable } \\
(\mathrm{n}=283)\end{array}$ & $\begin{array}{l}\text { Total } \\
(\mathrm{n}=516)(\%)\end{array}$ \\
\hline $\begin{array}{l}\text { Equipment of transportation } \\
\text { Incubator transport }\end{array}$ & 103 & 113 & $216(41.8)$ \\
$\quad$ Box & 77 & 99 & $176(34)$ \\
$\quad$ Kangaroo mother care & 68 & 56 & $124(24.2)$ \\
Respiratory support & & & $109(21.1)$ \\
$\quad$ Without respiratory support & 70 & 39 & $163(31.5)$ \\
$\quad$ Nasal cannula & 34 & 129 & $87(16.8)$ \\
$\quad$ Mask & 32 & 55 & $157(30.4)$ \\
$\quad$ T-piece resuscitator & 97 & 60 & \\
$\quad$ Mixsafe/neopuff & & & $93(18)$ \\
Intubated before transferred & 66 & 27 & $423(82)$ \\
$\quad$ Yes & 167 & 256 & $284(55)$ \\
$\quad$ No & & & $232(45)$ \\
IV fluid during transferred & 212 & 72 & $217(42)$ \\
$\quad$ Yes & 21 & 211 & $299(58)$ \\
$\quad$ No & & 129 & \\
Used monitor saturation & 88 & 154 & \\
$\quad$ Yes & 145 & & \\
$\quad$ No & & &
\end{tabular}

Table 3

Characteristics of neonates with unstable conditions during admitted in hospital

\begin{tabular}{ll}
\hline $\begin{array}{l}\text { Characteristics of neonates with unstable conditions } \\
\text { during admitted }\end{array}$ & Cases (n=283) (\%) \\
\hline Hypoglycaemia & $93(33)$ \\
Hypothermia & $51(18)$ \\
Hypoxia & $63(22)$ \\
Hypoperfusion & $28(10)$ \\
Incomplete laboratory workup & $48(17)$ \\
More than 1 conditions & $186(36)$ \\
\hline
\end{tabular}

\section{Discussion}

Sanglah Hospital is a tertiary hospital that receives referral patients from Bali and Nusa Tenggara and has a level III perinatology care system. In Bali, there is still no neonatal transportation system as there is in developed countries. It has affected the neonatal conditions on arrival, which most of them were unstable so that it accounts for higher morbidity and mortality. Stabilization during transport is as important as the pre transport stabilization.

The S.T.A.B.L.E training (sugar and safe care, temperature, airway, blood pressure, laboratory work, and emotional support) program is carried out on health care experts to find and stabilize sick babies after resuscitation or before the baby is referred (World Health Organization, 2003). The STABLE program is designed based on the principle of resuscitation priority when facing critical conditions, namely ABC (airway, breathing, and circulation). The STABLE program also strives for the baby to be "warm, pink, and sweet" as soon as possible within 1 hour. 
This study found total neonates admitted to the emergency room of Sanglah hospital during the study period were 588 neonates, in which 72 of them were excluded due to incomplete medical records. The total subjects included in the study were 516 neonates of which $54.8 \%$ were unstable. There was a male predominance noted in this study (68.3\%), which is consistent with the study conducted in India (Ravelli $e t$ al., 2011).

According to WHO, Indonesia is in rank ninth as the top 10 countries with the highest rates of preterm birth per 100 live births (Howson et al., 2012). In this study, prematurity was the main reason for referral (42.6\%). A study in India also found that prematurity is the main reason for referral in tertiary care (54.63\%) followed by sepsis (24.93\%) (Ravelli et al., 2011). Among premature neonates, gestational age was mostly in 28-32 weeks (30\%). A high incidence of premature neonates may be due to the weakness of antenatal program systems (Ravelli et al., 2011).

Most of the district hospitals in Bali do not have adequate perinatology facilities. On average in each district, there are only 1-2 hospitals that have level-II perinatology care, that provide care for infants born $\geq 32$-week gestation and weighing $\geq 1500$ g who have physiologic immaturity or who are moderately ill with problems that are expected to resolve rapidly (Howson et al., 2012).

Lasswell et al. reviewed 41 studies, which included $>113.000$ VLBW infants and found that VLBW infants born at non-level III hospitals had a $62 \%$ increase in odds of neonatal or predischarge mortality compared with those born at level III hospitals (adjusted odds ratio [aOR], 1.62; 95\% confidence interval [CI], 1.44-1.83) (Lasswell et al., 2010). Hence, the risk of death for VLBW infants born in level I or II facilities remained higher than those born within a level III facility.

Bali has wide demography, and lots of peripheral health centers reside in rural areas. In this study, most of the neonates (66.1\%) were referred from the peripheral hospital (outside Denpasar). Most neonates were referred from Denpasar (33.9\%), followed by Badung (14.7\%), and Gianyar (10.8\%). Denpasar as the most referral district was due to the densest population of all districts (Badan Pusat Statistik, 2020). There are lots of health care centers in Denpasar but still out of numbers compare to the population. Badung and Gianyar were the same, these two districts have dense population compare to other districts. These two regencies have a distance of approximately 30 kilometers from Sanglah Hospital. Perinatology facilities in these two regencies are more numerous than others but still limited compared to the needs so the referral numbers obtained are still high. The farthest regencies from Denpasar are Singaraja and Jembrana, which is around 50$70 \mathrm{~km}$. Both of these districts only have level 2 perinatology cares with limited capacity.

This study found that most of the neonates were referred to in condition of premature and transported with limited equipment, which made them prone to serious complications. Improving the survival of these populations can be done by stabilizes them using S.T.A.B.L.E criteria. In this study, there were $36 \%$ of neonates referred to a combination of more than one instability conditions. These could be because of the peripheral hospital were referring a neonate without prior stabilization. They might think to save the neonate's life by referring to them as fast as they could.

In this study, we found around 33\% of neonates were referred to a hypoglycaemic state. This condition could be related to the gestational age, most of them were premature and low birth weight. Some of these neonates were referred without an intravenous line (45\%) or inappropriate fluid, such as normal saline or $5 \%$ dextrose. The intravenous line should be inserted in sick neonates due to their fasting. Some problems also could be happened during transportation such as blocking or disruption of intravenous cannulation. Hypoglycemia especially in critically ill neonates can lead to mortality and serious lifelong neurodevelopmental sequela (Lasswell et al., 2010).

In this study, $18 \%$ of neonates were hypothermia during admission, most of them (85\%) were transported using a baby box. There were only $24.2 \%$ of neonates referred to kangaroo mother care, as incubator transport is not available in the majority of hospitals. The Kangaroo mother care method is useful to maintain a baby's temperature, reduce hypothermia and hypoglycaemia, especially among preterm babies.

Hypothermia 5 minutes after birth and at NICU admission varied among centers from $13 \%$ to $62 \%$ and from $25 \%$ to $75 \%$, respectively (de Almeida et al., 2014). Hypothermia at 5 minutes after birth and NICU admission was inversely related to gestational age, 35\% of neonates with gestational ages of 32 and 33 weeks were hypothermic at 5 minutes, and 40\% were hypothermic at NICU admission (de Almeida et al., 2014).

In this study, we found $22 \%$ of neonates were hypoxia during admission and only $18 \%$ of referred neonates were intubated before transportation. Intubation was mandatory for neonates with respiratory

Ekaputri, D. S., Sukmawati, M., Putra, P. J., Kardana, I. M., \& Artana, I. W. D. (2020). Characteristics of referral neonates in Sanglah Hospital: reviewed from the S.T.A.B.L.E program. International Journal of Health Sciences, 4(2), 31-39. https://doi.org/10.29332/ijhs.v4n2.447 
failure to maintain oxygen saturation of 88-92\%. During transportation, 58\% were transferred without pulse oximeter. Oxygen saturation monitoring using pulse oximetry is a reliable non-invasive method of monitoring arterial blood oxygenation saturation. Prolong hypoxia can cause poor prognosis to neonates, so pulse oximetry observation is mandatory during transport. Another noteworthy observation in this study was the high proportion of neonates were referred to with high oxygen concentration (100\% of fraction oxygen). Over-usage of oxygen treatment may cause lung injury and retinopathy in premature neonates (Anurekha et al., 2018; Gilbert et al., 2000; Dramawan, 2018).

Peripheral skin perfusion is one method to determine whether the circulation is adequate. This study found $11.5 \%$ of neonates came with hypoperfusion. Hypoperfusion condition could show whether the baby was shock or hypotensive condition. The neonates in shock have inadequate tissue perfusion and oxygenation. Rapid, effective management of shock is vital to prevent permanent tissue injury, multiple organ failure, and death (Null et al., 2016).

Laboratory analysis wasn't done in $17 \%$ of neonates transferred. Incomplete blood tests probably due to the limitation of facilities. A study by Null et al. (2016), showed the analyses of blood gases before and after transfers demonstrated significant improvements in blood pH and base deficit (Ravelli et al., 2011).

\section{Conclusion}

This study demonstrates there were 283 (54.8\%) neonates who came with an unstable condition. The main reason of transfer neonates is prematurity and low birth weight. Most of them come with unstable conditions that could lead to higher mortality and morbidity. This study emphasizes the importance of stabilization before and during transportation. The results of this study can be used as a reference for improvement in the neonatal transportation system in Bali.

\section{Limitation of this study}

This was an observational study among transferred neonates in our setting. This study was not analyzing the outcome of the neonates so the further prospective study is needed. This study was not observed when the UNSTABLE condition of neonates was happening, it could be happened in the referring hospital or while transport.

Acknowledgments

We are grateful to two anonymous reviewers for their valuable comments on the earlier version of this paper. 


\section{References}

Alasiry, E. (2016). Profil bayi rujukan saat masuk rawat ditinjau dari the stable program. Sari Pediatri, 13(4), 235-8.

Anurekha, V., \& Kumaravel, K. S. (2018). Satheesh kumar D. Clinical profile of neonates admitted to a neonatal intensive care unit at a referral hospital in South India. Int J Pediatr Res, 5(2), 72-77.

Badan Pusat Statistik, (2020), Kepadatan Penduduk Menurut Kabupaten/Kota di Bali, 2010-2019. [online].

Batki, A., Baron-Cohen, S., Wheelwright, S., Connellan, J., \& Ahluwalia, J. (2000). Is there an innate gaze module? Evidence from human neonates. Infant Behavior and Development,23(2), 223-229. https://doi.org/10.1016/S0163-6383(01)00037-6

Biederman, J., Faraone, S. V., Mick, E., Williamson, S., Wilens, T. E., Spencer, T. J., ... \& Zallen, B. (1999). Clinical correlates of ADHD in females: findings from a large group of girls ascertained from pediatric and psychiatric referral sources. Journal of the American Academy of Child \& Adolescent Psychiatry, 38(8), 966975. https://doi.org/10.1097/00004583-199908000-00012

Committee on fetus and newborn. (2018). Levels of neonatal care. Pediatrics, 130, 587-587.

de Almeida, M. F. B., Guinsburg, R., Sancho, G. A., Rosa, I. R. M., Lamy, Z. C., Martinez, F. E., ... \& de Cássia Silveira, R. (2014). Hypothermia and early neonatal mortality in preterm infants. The Journal of pediatrics, 164(2), 271-275. https://doi.org/10.1016/j.jpeds.2013.09.049

Dramawan, A. (2018). The influence of supportive psychotherapy toward patient anxiety to pre-hyperbaric therapy. International journal of health sciences, 2(3), 55-64. https://doi.org/10.29332/ijhs.v2n3.219

Gilbert, M., Busund, R., Skagseth, A., Nilsen, P. Å., \& Solbø, J. P. (2000). Resuscitation from accidental hypothermia of 13. 7 C with circulatory arrest. The Lancet, 355(9201), 375-376. https://doi.org/10.1016/S0140-6736(00)01021-7

Howson, C. P., Kinney, M. V., \& Lawn, J. E. (2012). March of Dimes, PMNCH, Save the children, WHO. Born too soon: the global action report on preterm birth. Geneva: World Health Organization.

Karlsen, (2018), Pre-transport/post-resuscitation stabilization care of sick infants' guidelines for neonatal healthcare providers. [online].

Lasswell, S. M., Barfield, W. D., Rochat, R. W., \& Blackmon, L. (2010). Perinatal regionalization for very lowbirth-weight and very preterm infants: a meta-analysis. Jama, 304(9), 992-1000. https://doi.org/10.1001/jama.2010.1226

Null, D., Crezee, K., \& Bleak, T. (2016). Noninvasive respiratory support during transportation. Clinics in Perinatology, 43(4), 741-754. https://doi.org/10.1016/j.clp.2016.07.009

Parekh, Z. R., Bharadwaj, R., Parmar, G., \& Shah, A. (2018). Study of Referral Pattern of Neonates at Tertiary Care Centre and Role of TOPS Score in Assessing Morbidity and Mortality. Natl J Community Med, 9(3), 157-60.

Peterson, S., Nsungwa-Sabiiti, J., Were, W., Nsabagasani, X., Magumba, G., Nambooze, J., \& Mukasa, G. (2004). Coping with paediatric referral-Ugandan parents' experience. The Lancet,363(9425), 1955-1956. https://doi.org/10.1016/S0140-6736(04)16411-8

Ravelli, A. C. J., Jager, K. J., De Groot, M. H., Erwich, J. J. H. M., Rijninks-van Driel, G. C., Tromp, M., ... \& Mol, B. W. J. (2011). Travel time from home to hospital and adverse perinatal outcomes in women at term in the Netherlands. BJOG: An International Journal of Obstetrics \& Gynaecology, 118(4), 457-465. https://doi.org/10.1111/j.1471-0528.2010.02816.x

World Health Organization, (2003), Managing newborn problems: a guide for doctors, nurses, and midwive. [online].

Ekaputri, D. S., Sukmawati, M., Putra, P. J., Kardana, I. M., \& Artana, I. W. D. (2020). Characteristics of referral neonates in Sanglah Hospital: reviewed from the S.T.A.B.L.E program. International Journal of Health Sciences, 4(2), 31-39. https://doi.org/10.29332/ijhs.v4n2.447 


\section{Biography of Authors}

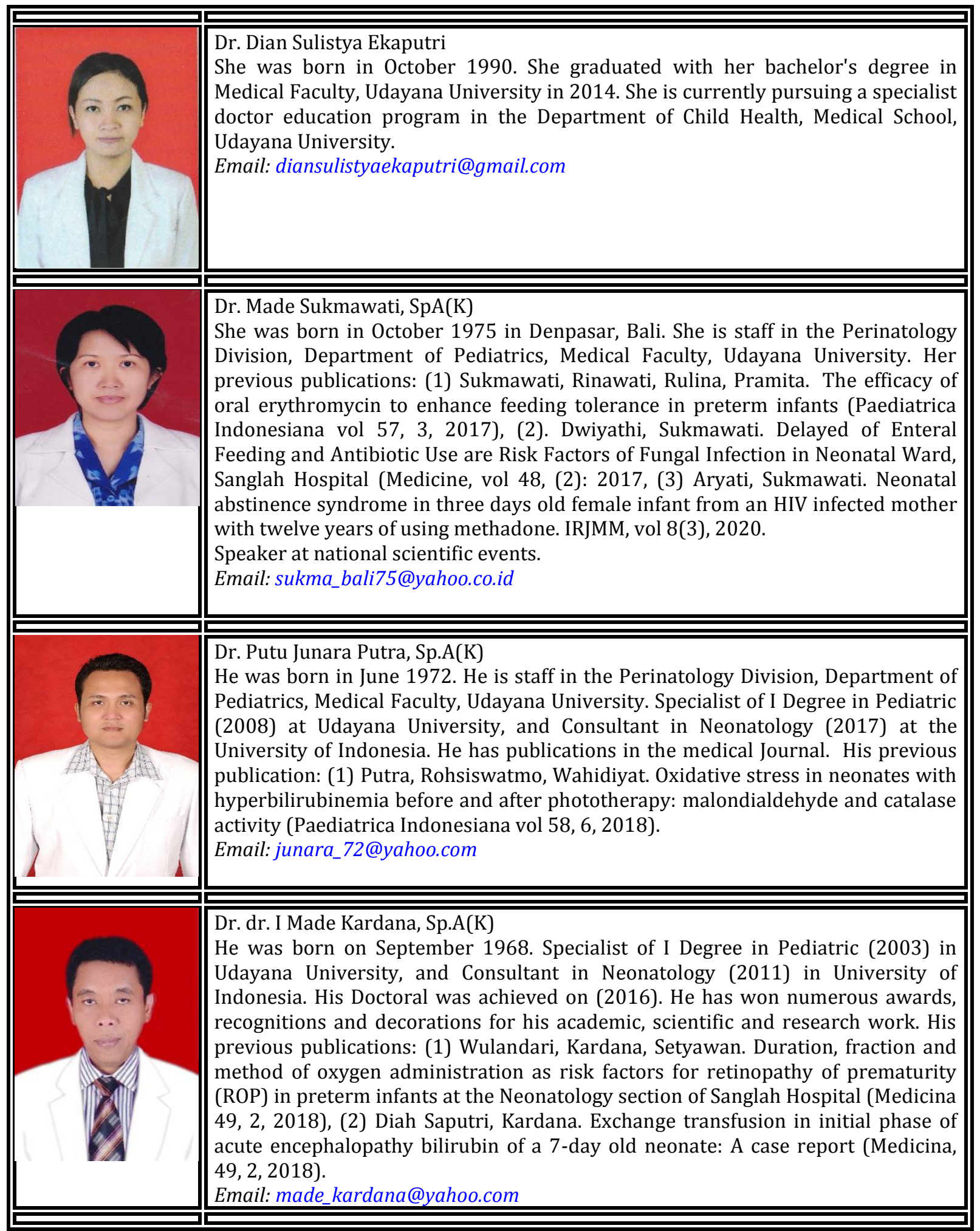




\begin{tabular}{|l|l||}
\hline & Dr. I Wayan Dharma Artana, Sp.A(K) \\
& He was born in March 1966. Specialist of I Degree in Pediatric (2005) at Udayana \\
& University, and Consultant in Neonatology (2012) at the University of Indonesia. \\
& He has publications in the medical Journal. His previous publications: (1) Alissya, \\
& Artana, Sukmawati. The prevalence of neonatal meningitis and the factors \\
affecting clinically sepsis in the NICU at Sanglah Hospital Denpasar (Medicine, vol \\
48, 2, 2017), (2) Maharani, Haksari, Artana. Risk factors for hearing loss in \\
neonates (Paediatrica Indonesiana vol 55, 6, 2016). Speaker at national scientific \\
events. \\
Email: dharma.artana@yahoo.com \\
\hline
\end{tabular}

Ekaputri, D. S., Sukmawati, M., Putra, P. J., Kardana, I. M., \& Artana, I. W. D. (2020). Characteristics of referral neonates in Sanglah Hospital: reviewed from the S.T.A.B.L.E program. International Journal of Health Sciences, 4(2), 31-39. https://doi.org/10.29332/ijhs.v4n2.447 